\title{
Constructive Fuzzy Sets with Similarity Semantics
}

\author{
W.N. Liu J.T. Yao Y.Y. Yao \\ Department of Computer Science, University of Regina \\ Regina, Saskatchewan, Canada S4S 0A2 \\ \{jtyao\}@cs.uregina.ca
}

\begin{abstract}
Semantic interpretation of membership functions is still one of the unsettled issues of fuzzy set theory, although some proposals have been made and studied. In this paper, we present an alternative formulation called the constructive model of fuzzy sets, motivated by the concept of constructive mathematics. The model makes explicit use of knowledge regarding relationships between elements of a universal set, and a constructive method. As an example, we show that s-fuzzy sets can be constructed based on similarity and elementary fuzzy sets. Properties of the constructed fuzzy set system are examined in qualitative and quantitative terms.
\end{abstract}

\section{INTRODUCTION}

The theory of fuzzy sets [26] is a generalization of set theory [9]. A fuzzy set is generated by changing two-value memberships defining a crisp set to inexact or partial memberships [10]. Although the semantic interpretation of fuzzy memberships is interesting and significant, it is still one of the unsettled issues in the literature of fuzzy sets. Dubois and Prade examined three main semantics for fuzzy memberships, namely, similarity, preference and uncertainty [5]. Each of them underlines a particular class of applications. The fuzzy sets studied in a particular semantic context are called qualitative fuzzy sets [13].

It is argued that fuzzy sets can be defined by primitive notions with semantic interpretations, such as distance, frequency and cost [21]. Equivalence classes can be treated as primitive notions and they can be defined and explained using an information table [17], [22]. A fuzzy set can be constructed by equivalence classes. The membership value of an object in the derived fuzzy set is interpreted as the conditional probability that the object belongs to a prototype set given that the object belongs to some equivalence class [16], [21].

The fuzzy sets that can work as primitive notions emerge in the information-driven tasks where feature comparison is a fundamental operation, such as approximate reasoning [7] and pattern classification [18]. The similarity relationships between objects can be defined and explained using a distance metric. A fuzzy set is naturally derived in terms of similarity to a prototype. The membership of an arbitrary object is the degree of similarity of the object to the prototype; the more similar an object is to the prototype, the greater its membership grade should be. A method by which a qualitative fuzzy set can be generated in terms of similarity relationships to prototypes in a prototype set has previously been presented [4], [5], [6], [7], but there still lacks of further exploration for these types of fuzzy sets in a constructive view.
This paper presents a constructive model of fuzzy sets. The model makes explicit use of knowledge regarding relationships between objects, and a constructive method. As an example, we study constructive fuzzy sets with similarity semantics. This paper also examines the quantitative and qualitative features of constructive fuzzy sets with similarity semantics.

\section{Classical Formulation of Fuzzy Sets}

Let $U$ ba a finite and non-empty set. A fuzzy set $\mathcal{A}$ of $U$ is defined by a membership function:

$$
\mu_{\mathcal{A}}: U \rightarrow[0,1] .
$$

One or several fuzzy sets can construct a new fuzzy set by set-theoretic operations: complement, intersection and union. The membership function of the derived fuzzy set is defined on the membership functions of the fuzzy sets involved:

$$
\begin{aligned}
\mu_{\neg \mathcal{A}}(x) & =c o\left(\mu_{\mathcal{A}}(x)\right), \\
\mu_{\mathcal{A} \cap \mathcal{B}}(x) & =t\left(\mu_{\mathcal{A}}(x), \mu_{\mathcal{B}}(x)\right), \\
\mu_{\mathcal{A} \cup \mathcal{B}}(x) & =s\left(\mu_{\mathcal{A}}(x), \mu_{\mathcal{B}}(x)\right),
\end{aligned}
$$

where the complement, intersection and union operators are defined by negator, triangular norm and triangular conorm [12], [19], respectively, which are generalizations of the connectives from Boolean logic [2]. Different pairs of triangular norm and triangular conorm can derive different fuzzy set systems [24]. This paper considers the standard minmax system proposed by Zadeh [26]:

$$
\begin{aligned}
\mu_{\neg \mathcal{A}}(x) & =1-\mu_{\mathcal{A}}(x), \\
\mu_{\mathcal{A} \cap \mathcal{B}}(x) & =\max \left(\mu_{\mathcal{A}}(x), \mu_{\mathcal{B}}(x)\right), \\
\mu_{\mathcal{A} \cup \mathcal{B}}(x) & =\min \left(\mu_{\mathcal{A}}(x), \mu_{\mathcal{B}}(x)\right) .
\end{aligned}
$$

The above discussion shows that fuzzy set-theoretic operations lack of the qualities regarding semantics of the fuzzy sets involved.

On the other hand, Fuzzy set $\mathcal{A}$ can be approximately described by its core and support:

$$
\begin{aligned}
& \operatorname{core}\left(\mu_{\mathcal{A}}\right)=\left\{x \in U \mid \mu_{\mathcal{A}}(x)=1\right\}, \\
& \operatorname{support}\left(\mu_{\mathcal{A}}\right)=\left\{x \in U \mid \mu_{\mathcal{A}}(x) \geq 0\right\} .
\end{aligned}
$$

Compared with abstract membership functions, the coresupport structure of a fuzzy set has clear semantic interpretation: the core represents the intension or attributes of a fuzzy concept and the support represents the extension of the fuzzy concept. The following restrictions on abstract fuzzy 
set-theoretic operations can be obtained from the set-theoretic operations of the cores and supports [21]:

$$
\begin{array}{ll}
\operatorname{core}\left(\mu_{\mathcal{A}}\right) & =\neg \operatorname{support}\left(\mu_{\mathcal{A}}\right), \\
\operatorname{support}\left(\mu_{\mathcal{A}}\right) & =\neg \operatorname{core}\left(\mu_{\mathcal{A}}\right), \\
\operatorname{core}\left(\mu_{\mathcal{A} \cap \mathcal{B}}\right) & =\operatorname{core}\left(\mu_{\mathcal{A}}\right) \cap \operatorname{core}\left(\mu_{\mathcal{B}}\right), \\
\operatorname{core}\left(\mu_{\mathcal{A} \cup \mathcal{B}}\right) & \supseteq \operatorname{core}\left(\mu_{\mathcal{A}}\right) \cup \operatorname{core}\left(\mu_{\mathcal{B}}\right), \\
\operatorname{support}\left(\mu_{\mathcal{A} \cap \mathcal{B}}\right) & \subseteq \operatorname{support}\left(\mu_{\mathcal{A}}\right) \cap \operatorname{support}\left(\mu_{\mathcal{B}}\right), \\
\operatorname{support}\left(\mu_{\mathcal{A} \cup \mathcal{B}}\right) & =\operatorname{support}\left(\mu_{\mathcal{A}}\right) \cup \operatorname{support}\left(\mu_{\mathcal{B}}\right) .
\end{array}
$$

Since the above properties are unrelated with fuzzy settheoretic operators, they reflect the qualitative properties of fuzzy set-theoretic operations.

The notion of fuzzy sets also provides a natural basis for generalizing the binary relations between two objects [14]. The similarity [25] between objects is a pervasive fuzzy binary relation, which may come from empirical perception:

$$
S: U \times U \rightarrow[0,1]
$$

where $[0,1]$ may be viewed as a set of graded truth values that represent the degree to which objects are similar. If $S(x, y)=1$, then $x$ and $y$ are perceived to be too similar to be discernible, whereas $S(x, y)=0$ indicates that $x$ and $y$ are totally unrelated or independent.

Under a similarity relation $S, U$ is a metric space, i.e. for any two objects $x, y \in U$, they satisfy the following conditions [15], [25]:

$$
\begin{array}{ll}
S(x, x) & =1, \\
S(x, y) & =S(y, x), \\
S(x, t) * S(t, y) & \leq S(x, y), t \in U .
\end{array}
$$

Condition (1) implies that any object cannot be distinguished from itself under the similarity knowledge. Condition (2) shows that judgement of similarity is symmetrical, which has been viewed as a stand for all theoretical treatment of similarity [20]. $S(y, x)$ is also called the inverse relation of $S$ [14]. Condition (3) is a generalization of the triangle inequality, where the binary operator $*$ is a triangular norm. In the view of [19], condition (3) implies that our knowledge of the similarity between $x$ and $y$ depends on our knowledge of the similarity between $x$ and $t$ and likewise for $t$ and $y$.

To summarize the discussion, the membership grades of a fuzzy set are not explicitly related to a metric space; fuzzy set-theoretic operations are not related to the semantics of the fuzzy sets involved. As a consequence, there is a lack of operational interpretations for membership grades and fuzzy set-theoretic operations. The core-support structure of fuzzy sets can partially interpret abstract fuzzy sets and fuzzy settheoretic operations. On the other hand, similarity is closely related with basic measurement of quantities, and serves as a measurement of the relationship between objects. Similarity has intuitive qualities and empirical grounds. The quantities of similarity can help measure fuzzy set memberships.

\section{Constructive Fuzzy Sets}

Instead of defining a fuzzy set with membership functions, fuzzy sets could be constructed. A constructive fuzzy set model can be expressed as a triplet $(U, K, M)$ [21]. A similar structure was used on the study of a granular computing approach for problem solving [27]. The $U$ in the triplet represents a non-empty set and finite of objects. Knowledge $K$ is about relationships between objects of $U$. $M$ refers to a method by which fuzzy sets are constructed. Since the construction of fuzzy sets is an inseparable part of the theory, we may provide a semantic interpretation of fuzzy sets [21].

Let $P \in U$ be a set of prototypes. For each object $p \in P$, a fuzzy set can be defined by the membership function of $[p]_{K}$ which is a class or neighborhood [23] of $p$ formed by $K$ :

$$
\mu_{\{p\}}(x)=[p]_{K}(x),
$$

where $[p]_{K}=\{x \in U \mid p K x\} . \mu_{\{p\}}$ can be interpreted in terms of the semantics of $K . \mu_{\{p\}}$ can therefore be viewed as a primitive notion. We call $\mu_{\{p\}}$ an elementary fuzzy set of $p$. When $K$ is an equivalence relation, $[p]_{K}$ is an equivalence class and $\mu_{\{p\}}$ a crisp set.

Generally, a fuzzy set can be constructed from a prototype set $P$ by method $M$ :

$$
\mu_{\{P\}}(x)=M\left(\left\{\mu_{\{p\}}(x)\right\}\right),
$$

where $\left\{\mu_{\{p\}}(x)\right\}$ represents the set of elementary fuzzy sets derived from all prototypes of $P$. $M$ may be a fuzzy settheoretic operator or a fuzzy aggregation operator. We call $\mu_{\{P\}}$ a constructive fuzzy set with semantics $K \cdot \mu_{\{P\}}(x)$ can be interpreted in terms of method $M$ and the elementary fuzzy sets involved. A case is that when $K$ is an equivalence relation over $U$, a prototype set $P$ can derive a fuzzy set as follows [16]:

$$
\mu_{\{P\}}(x)=\frac{\left|[x]_{K} \cap P\right|}{\left|[x]_{K}\right|} .
$$

Here $\mu_{\{P\}}(x)$ is actually the addition of all $\mu_{\{p\}}(x), p \in P$, which accords with the addition law of probability.

In practice, similarity may refer to the distance, cost, and frequency measurement between objects. When a prototype and a similarity measure are available, a fuzzy set is naturally derived from the comparison of objects to the prototype [3], [18]. We call the fuzzy set an elementary $s$-fuzzy set. Let object $p$ be a prototype abstracted from $U$. Assume that $S$ represents the similarity measure of objects. The elementary $s$-fuzzy set looks like:

$$
\mu_{\{p\}}(x)=[p]_{S}=S(x, p) .
$$

The prototype $p$ can also be viewed as a seed from which $\mu_{\{p\}}$ is derived by the similarity measure $S . \mu_{\{p\}}(x)$ is the degree of similarity of $x$ to $p$. Particularly, it is reasonable to assume that

$$
\mu_{\emptyset}(x)=0 .
$$

Since $p \in \operatorname{core}\left(\mu_{\{p\}}\right)$, a $s$-fuzzy set is normal [11]. 
For any $p^{\prime} \in \operatorname{core}\left(\mu_{\{p\}}\right)$ and $p^{\prime} \neq p$, the following inequalities co-exist:

$$
\begin{aligned}
& S(x, p)=S(x, p) * S\left(p, p^{\prime}\right) \leq S\left(x, p^{\prime}\right), \\
& S\left(x, p^{\prime}\right)=S\left(x, p^{\prime}\right) * S\left(p, p^{\prime}\right) \leq S(x, p) .
\end{aligned}
$$

Therefore, $p$ and $p^{\prime}$ can derive the same $s$-fuzzy set, which corresponds to the interpretation of $S(x, y)=1$ in the previous section. If $p^{\prime}$ is not in $\operatorname{core}\left(\mu_{\{p\}}\right), S\left(p, p^{\prime}\right)<1$, which implies that $\mu_{\{p\}} \neq \mu_{\left\{p^{\prime}\right\}}$. Therefore, different prototypes derive distinct elementary $s$-fuzzy sets. Let $[p]=\operatorname{core}\left(\mu_{\{p\}}\right)$. An elementary $s$-fuzzy set defined by the membership function (6) can be denoted as $\mu_{[p]}$.

Theorem 1: If prototypes $p_{1}$ and $p_{2}$ satisfy that $S\left(p_{1}, p_{2}\right)<$ $1, \mu_{\left[p_{1}\right]} \neq \mu_{\left[p_{2}\right]}$ and $\left[p_{1}\right] \cap\left[p_{2}\right]=\emptyset$.

Let $P=\left\{p_{1}, p_{2}\right\}$. According to the constructive method of fuzzy sets given by [4], [5], [6], [7], consider the union of two elementary $s$-fuzzy sets $\mu_{p_{1}}$ and $\mu_{p_{2}}$ :

$$
\begin{aligned}
\mu_{P}(x) & =\max \left(\mu_{\left[p_{1}\right]}(x), \mu_{\left[p_{2}\right]}(x)\right), \\
& =\max \left(S\left(x, p_{1}\right), S\left(x, p_{2}\right)\right) .
\end{aligned}
$$

Let $[P]=\operatorname{core}\left(\mu_{P}\right)$. The fuzzy set $\mu_{P}$ satisfies that

$$
[P]=\left[p_{1}\right] \cup\left[p_{2}\right] .
$$

More generally, for any subset $P \subseteq U$,

$$
\mu_{P}(x)=\bigvee_{p \in P} \mu_{[p]}(x),
$$

and

$$
[P]=\bigcup_{p \in P}[p] .
$$

Membership function (9) can be rewritten as:

$$
\mu_{P}(x)=\bigvee_{p \in[P]} \mu_{[p]}(x) .
$$

We call fuzzy set $\mu_{P}$ a $s$-fuzzy set. A $s$-fuzzy set can be represented by a union of the elementary ones derived from prototypes of $P$. Since no strong scientific tradition supports the constructive method of $s$-fuzzy sets, $\mu_{P}$ has no explicit optional interpretation. $\mu_{P}$ may be interpreted as the image of $P$ through the relation $S$ [4]. $\mu_{P}$ may also be interpreted as a fuzzy set close to $P[6]$.

Theorem 2: If a set of elementary $s$-fuzzy sets $\mu_{\left[p_{1}\right]}, \mu_{\left[p_{2}\right]}, \ldots, \mu_{\left[p_{n}\right]}$ satisfy the following conditions:

$$
\begin{aligned}
{\left[p_{i}\right] \cap\left[p_{j}\right] } & =\emptyset, \quad i \neq j, \\
\bigcup_{i=1}^{n}\left[p_{i}\right] & =U,
\end{aligned}
$$

then these $s$-fuzzy sets constitute a fuzzy quotient set [8] of $U$.
Proof: It is easy to verify the following properties:

$$
\begin{gathered}
\bigvee_{i=1}^{n} \mu_{\left[p_{i}\right]}(x)=1, \\
\bigvee_{x \in U} \mu_{\left[p_{i}\right]}(x)=1, \\
\bigvee_{x \in U}\left(\mu_{\left[p_{i}\right]}(x) \wedge \mu_{\left[p_{j}\right]}(x)\right)<1 \text { whenever } i \neq j .
\end{gathered}
$$

On the other hand, for any $a, b \in U$,

$$
\mu_{[a]}(x) \bigwedge \mu_{[b]}(x) \leq \mu_{[a]}(b) \bigwedge \mu_{[b]}(a) .
$$

Therefore,

$$
\bigvee_{x \in U} \mu_{[a]}(x) \bigwedge \mu_{[b]}(x)=\mu_{[a]}(b) \bigwedge \mu_{[b]}(a)
$$

Corollary 1: If a set of elementary $s$-fuzzy sets constitute a fuzzy quotient set $\prod_{S}$ of $U$, then any $s$-fuzzy set is a union of the members of some subset of $\prod_{S}$.

This section presents a constructive model for fuzzy sets. Considering a set of prototypes, each prototype forms an elementary fuzzy set based on knowledge $K$. Elementary fuzzy sets can be interpreted by knowledge $K$. They are atomic and act as building blocks of the constructive model. A fuzzy set can be built on these elementary fuzzy sets by a method. We examine constructive fuzzy sets under similarity knowledge. An elementary $s$-fuzzy set directly comes from the similarity of objects to a prototype. Any $s$-fuzzy set is the union of some elementary $s$-fuzzy sets.

\section{The Characterization of $s$-Fuzzy Set Systems}

We study the set-theoretic operations as well as the coresupport structure of $s$-fuzzy sets. Quantitative and qualitative characteristics of $s$-fuzzy sets are presented.

\section{A. The Quantitative Characterization of s-Fuzzy Sets}

The basic quantitative features of $s$-fuzzy sets include inclusion, intersection and complement operation of the sets.

The first feature of $s$-fuzzy sets is about the relation between the prototype sets and $s$-fuzzy sets:

Property 1:

$$
\begin{aligned}
& P_{1}=P_{2} \Rightarrow \mu_{P_{1}}=\mu_{P_{2}}, \\
& P_{1} \subseteq P_{2} \Rightarrow \mu_{P_{1}} \subseteq \mu_{P_{2}} .
\end{aligned}
$$

This property shows that $s$-fuzzy sets are nondecreasing with respect to the the inclusion of prototype sets. 
The next feature of $s$-fuzzy sets is about the intersection between two $s$-fuzzy sets. The intersection of two $s$-fuzzy sets may not be a $s$-fuzzy set, especially when $\left[P_{1}\right] \cap\left[P_{2}\right]=\emptyset$.

$$
\begin{aligned}
\left(\mu_{P_{1}} \cap \mu_{P_{2}}\right)(x) & =\bigvee_{p_{1} \in P_{1}} \mu_{\left[p_{1}\right]}(x) \bigwedge \bigvee_{p_{2} \in P_{2}} \mu_{\left[p_{2}\right]}(x) \\
& =\bigvee_{p_{1} \in P_{1}, p_{2} \in P_{2}}\left(\mu_{\left[p_{1}\right]}(x) \bigwedge \mu_{\left[p_{2}\right]}(x)\right) \\
& \leq \bigvee_{p_{1} \in P_{1}, p_{2} \in P_{2}}\left(\mu_{\left[p_{1}\right]}\left(p_{2}\right) \bigwedge \mu_{\left[p_{2}\right]}\left(p_{1}\right)\right) \\
& =\bigvee_{p_{1} \in P_{1}, p_{2} \in P_{2}} S\left(p_{1}, p_{2}\right) .
\end{aligned}
$$

Property 2: The constraint for fuzzy intersection of $s$-fuzzy sets is:

$$
\bigvee_{p \in P_{1} \cap P_{2}} S(x, p) \leq\left(\mu_{P_{1}} \cap \mu_{P_{2}}\right)(x) \leq \bigvee_{p_{1} \in P_{1}, p_{2} \in P_{2}} S\left(p_{1}, p_{2}\right) .
$$

The complement of a $s$-fuzzy set is not a $s$-fuzzy set. When a prototype set is a singleton, $\left(\neg \mu_{p}\right)(x)$ may be interpreted as the degree of dissimilarity of object $x$ to the prototype $p$ :

$$
\left(\neg \mu_{[p]}\right)(x)=1-S(x, p)=S^{c}(x, p) .
$$

Property 3:

$$
\left(\neg \mu_{P}\right)(x)=1-\bigvee_{p \in[P]} \mu_{[p]}(x)=\bigwedge_{p \in[P]} \mu_{[p]}(x) .
$$

Property 4: There at least exists an object in $U$ satisfying

$$
\left(\neg \mu_{P}\right)(x)=0 .
$$

Property 5:

$$
P_{1} \subseteq P_{2} \Rightarrow\left(\neg \mu_{P_{1}}\right) \supseteq\left(\neg \mu_{P_{2}}\right) .
$$

This property shows that $s$-fuzzy sets are non-increasing with respect to the the inclusion of prototype sets.

Property 6: For any $x \in[P]$,

$$
\begin{aligned}
& \left(\mu_{P} \cup \neg \mu_{P}\right)(x)=1, \\
& \left(\mu_{P} \cap \neg \mu_{P}\right)(x)=0 .
\end{aligned}
$$

The Property 6 implies that we can know exactly which object belongs to a $s$-fuzzy set or does not belong to the complement of a $s$-fuzzy set. Finally, the boundary conditions of $s$-fuzzy sets and their compliments are:

Property 7:

$$
\begin{gathered}
\mu_{U}(x)=1, \mu_{\emptyset}(x)=0, \\
\left(\neg \mu_{\emptyset}\right)(x)=1, \mu_{\emptyset}(x)=1 .
\end{gathered}
$$

In this subsection, we examined the set-theoretic operations of $s$-fuzzy sets. Besides the union of $s$-fuzzy sets, the intersection and complement of $s$-fuzzy sets cannot be compositional under a similarity metric. Dubois and Prade have pointed out that the min-max system widely used in the literature of fuzzy set cannot precisely account for similarity semantics [5]. There exists a gap between pure set-theoretical methods and constructive methods in the literature of fuzzy sets.

\section{B. The Qualitative Characterization of s-Fuzzy Sets}

We use core-support structure and its set-theoretic operation to interpret the qualitative properties of $s$-fuzzy sets.

The relation between a prototype set and a core-support structure is that the prototype set of a $s$-fuzzy set is a subset of the core of the $s$-fuzzy set; the support of a $s$-fuzzy set reflects the extension of prototype outspread under a similarity measurement. We first explore the core-support structure of $s$-fuzzy sets.

\section{Property 8:}

$$
\begin{aligned}
\operatorname{core}\left(\mu_{P}\right) & =\left\{x \in U \mid \mu_{P}(x)=1\right\} \\
& =\{x \in U \mid \exists p \in P, S(x, p)=1\} \\
& =\bigcup_{p \in P}[p] \\
& =\overline{\operatorname{apr}}(P)=[P] ; \\
\operatorname{core}\left(\neg \mu_{P}\right) & =\left\{x \in U \mid \forall p \in P, S^{c}(x, p)=1\right\} \\
& =\{x \in U \mid \forall p \in P, S(x, p)=0\} ;
\end{aligned}
$$

$$
\begin{aligned}
\operatorname{support}\left(\mu_{P}\right) & =\left\{x \in U \mid \mu_{P}(x)>0\right\} \\
& =\{x \in U \mid \exists p \in P, S(x, p)>0\} \\
& =U-\{x \in U \mid \forall p \in P, S(x, p)=0\} \\
& =U-\operatorname{core}\left(\neg \mu_{P}\right)=\neg \operatorname{core}\left(\neg \mu_{P}\right) ;
\end{aligned}
$$

$$
\begin{aligned}
\operatorname{support}\left(\neg \mu_{P}\right) & =\neg \operatorname{core}\left(\mu_{P}\right) \\
& =\neg \overline{\operatorname{apr}}(P) \\
& =U-[P] .
\end{aligned}
$$

The core-support structure of fuzzy sets in the theory of rough sets can be described by the lower bound and upper bound of the prototype set under the equivalence knowledge $E$ :

$$
\begin{aligned}
\operatorname{core}\left(\mu_{P}^{E}\right) & =\cup\left\{x \in U \mid[x]_{E} \subseteq P\right\}=\underline{\operatorname{apr}}(P), \\
\operatorname{support}\left(\mu_{P}^{E}\right) & =\cup\left\{x \in U \mid[x]_{E} \cap P \neq \emptyset\right\}=\overline{\operatorname{apr}}(P) .
\end{aligned}
$$

The core-support structure of $s$-fuzzy sets is complex and has to be described together by (11), (12), (13) and (14). The relation between the two types of core-support structures can 
be expressed as:

\section{Property 9.}

$\operatorname{core}\left(\neg \mu_{\neg P}\right) \subseteq \operatorname{core}\left(\mu_{P}^{E}\right) \subseteq \operatorname{support}\left(\mu_{P}^{E}\right) \subseteq \operatorname{core}\left(\mu_{P}\right)$.

We can easily get the boundary conditions of $\operatorname{core}\left(\mu_{P}\right)$ and $\operatorname{support}\left(\mu_{P}\right)$ as well as core $\left(\neg \mu_{P}\right)$ and $\operatorname{support}\left(\neg \mu_{P}\right)$ :

Property 10:

$$
\begin{aligned}
\operatorname{core}\left(\mu_{\emptyset}\right) & =\operatorname{support}\left(\mu_{\emptyset}\right)=\emptyset, \\
\operatorname{core}\left(\mu_{U}\right) & =\operatorname{support}\left(\mu_{U}\right)=U, \\
\operatorname{core}\left(\neg \mu_{\emptyset}\right) & =\operatorname{support}\left(\neg \mu_{\emptyset}\right)=U, \\
\operatorname{core}\left(\neg \mu_{U}\right) & =\operatorname{support}\left(\neg \mu_{U}\right)=\emptyset .
\end{aligned}
$$

For the complement, intersection and union of prototype sets, we can get the following conclusions:

$$
\begin{aligned}
& \text { Property 11: } \\
& \operatorname{core}\left(\mu_{\neg P}\right) \quad=\overline{\operatorname{apr}}(\neg P)=\neg \underline{\operatorname{apr}}(P) ; \\
& \operatorname{support}\left(\mu_{\neg P}\right) \quad=\quad \neg \operatorname{core}\left(\neg \mu_{\neg P}\right) \\
& \supseteq \neg \underline{\operatorname{apr}}(P) \text {; } \\
& \operatorname{core}\left(\neg \mu_{\neg P}\right) \quad=\quad\left\{x \in U \mid \forall p \in \neg P, S^{c}(x, p)=1\right\} \\
& =\{x \in U \mid \forall p \in \neg P, S(x, p)=0\} \\
& \subseteq \operatorname{apr}(P) \text {; } \\
& \operatorname{support}\left(\neg \mu_{\neg P}\right) \quad=\quad \neg \operatorname{core}\left(\mu_{\neg P}\right) \\
& =\neg \overline{a p r}(\neg P) \text {; } \\
& \operatorname{core}\left(\mu_{P_{1} \cap P_{2}}\right) \quad=\overline{a p r}\left(P_{1} \cap P_{2}\right) \\
& \subseteq \overline{\operatorname{apr}}\left(P_{1}\right) \cap \overline{\operatorname{apr}}\left(P_{2}\right) \\
& =\operatorname{core}\left(\mu_{P_{1}}\right) \cap \operatorname{core}\left(\mu_{P_{2}}\right) \text {; } \\
& \operatorname{support}\left(\mu_{P_{1} \cap P_{2}}\right)=\left\{x \in U \mid \mu_{P_{1} \cap P_{2}}(x)>0\right\} \\
& =\left\{x \in U \mid \exists p \in P_{1} \cap P_{2}, S(x, p)>0\right\} \\
& \subseteq\left\{x \in U \mid \exists p \in P_{1}, S(x, p)>0\right\} \\
& \cap\left\{x \in U \mid \exists p \in P_{2}, S(x, p)>0\right\} \\
& =\operatorname{support}\left(\mu_{P_{1}}\right) \cap \operatorname{support}\left(\mu_{P_{2}}\right) \text {; } \\
& \operatorname{core}\left(\mu_{P_{1} \cup P_{2}}\right) \quad=\overline{a p r}\left(P_{1} \cup P_{2}\right) \\
& =\overline{\operatorname{apr}}\left(P_{1}\right) \cup \overline{\operatorname{apr}}\left(P_{2}\right) \\
& =\operatorname{core}\left(\mu_{P_{1}}\right) \cup \operatorname{core}\left(\mu_{P_{2}}\right) \text {; } \\
& \operatorname{support}\left(\mu_{P_{1} \cup P_{2}}\right)=\left\{x \in U \mid \mu_{P_{1} \cup P_{2}}(x)>0\right\} \\
& =\left\{x \in U \mid \exists p \in P_{1} \cup P_{2}, S(x, p)>0\right\}
\end{aligned}
$$

$$
\begin{array}{ll}
= & \left\{x \in U \mid \exists p \in P_{1}, S(x, p)>0\right\} \\
\cup & \left\{x \in U \mid \exists p \in P_{2}, S(x, p)>0\right\} \\
= & \text { support }\left(\mu_{P_{1}}\right) \cup \operatorname{support}\left(\mu_{P_{2}}\right) .
\end{array}
$$

For the complement, intersection and union of $s$-fuzzy sets, the following properties hold.

Property 12:

$$
\begin{aligned}
\operatorname{core}\left(\mu_{P_{1}} \cap \mu_{P_{2}}\right) & =\operatorname{core}\left(\mu_{P_{1}}\right) \cap \operatorname{core}\left(\mu_{P_{2}}\right) \\
& =\overline{\operatorname{apr}}\left(P_{1}\right) \cap \overline{\operatorname{apr}}\left(P_{2}\right) \\
& \supseteq \overline{\operatorname{apr}}\left(P_{1} \cap P_{2}\right)=\operatorname{core}\left(\mu_{P_{1} \cap P_{2}}\right) ; \\
\operatorname{support}\left(\mu_{P_{1}} \cap \mu_{P_{2}}\right) & \subseteq \operatorname{support}\left(\mu_{P_{1}}\right) \cap \operatorname{support}\left(\mu_{P_{2}}\right) \\
& =\neg \operatorname{core}\left(\neg \mu_{P_{1}}\right) \cap \neg \operatorname{core}\left(\neg \mu_{P_{2}}\right) \\
& =\neg\left(\operatorname{core}\left(\neg \mu_{P_{1}}\right) \cup \operatorname{core}\left(\neg \mu_{P_{2}}\right)\right),
\end{aligned}
$$

Since,

$$
\begin{array}{ll}
\operatorname{core}\left(\neg \mu_{P_{1}}\right) \cup \operatorname{core}\left(\neg \mu_{P_{2}}\right) & \supseteq \operatorname{core}\left(\neg \mu_{P_{1} \cap P_{2}}\right), \\
\neg\left(\operatorname{core}\left(\neg \mu_{P_{1}}\right) \cup \operatorname{core}\left(\neg \mu_{P_{2}}\right)\right) & \subseteq \neg \operatorname{core}\left(\neg \mu_{P_{1} \cap P_{2}}\right) .
\end{array}
$$

Therefore,

$$
\begin{aligned}
\operatorname{support}\left(f_{P_{1}} \cap f_{P_{2}}\right) & \subseteq \neg \operatorname{core}\left(\neg f_{P_{1} \cap P_{2}}\right) ; \\
\operatorname{support}\left(\mu_{P_{1}} \cup \mu_{P_{2}}\right) & =\operatorname{support}\left(\mu_{P_{1}}\right) \cup \operatorname{support}\left(\mu_{P_{2}}\right) \\
& =\left\{x \in U \mid \exists p_{1} \in P_{1}, S\left(x, p_{1}\right)>0\right\} \\
& \cup\left\{x \in U \mid \exists p_{2} \in P_{2}, S\left(x, p_{2}\right)>0\right\} \\
& =\left\{x \in U \mid \exists p \in P_{1} \cup P_{2}, S(x, p)>0\right\} \\
& =\operatorname{support}\left(\mu_{P_{1} \cup P_{2}}\right) ; \\
\operatorname{core}\left(\mu_{P_{1}} \cup \mu_{P_{2}}\right) & \supseteq \operatorname{core}\left(\mu_{P_{1}}\right) \cup \operatorname{core}\left(\mu_{P_{2}}\right) \\
& \supseteq \overline{\operatorname{apr}}\left(P_{1}\right) \cup \overline{\operatorname{apr}}\left(P_{2}\right) \\
& =\overline{\operatorname{apr}}\left(P_{1} \cup P_{2}\right) .
\end{aligned}
$$

We also get the following conclusions about a $s$-fuzzy set and its complement:

Property 13:

$$
\begin{aligned}
\operatorname{core}\left(\mu_{P} \cap \neg \mu_{P}\right) & =\operatorname{core}\left(\mu_{P}\right) \cap \operatorname{core}\left(\neg \mu_{P}\right) \\
& =\operatorname{core}\left(\mu_{P}\right) \cap \neg \operatorname{support}\left(\mu_{P}\right)=\emptyset ; \\
\operatorname{support}\left(\mu_{P} \cap \neg \mu_{P}\right) & \subseteq \operatorname{support}\left(\mu_{P}\right) \cap \operatorname{support}\left(\neg \mu_{P}\right) \\
& =\operatorname{support}\left(\mu_{P}\right) \cap \neg \operatorname{core}\left(\mu_{P}\right) \\
& =\operatorname{support}\left(\mu_{P}\right)-\operatorname{core}\left(\mu_{P}\right) ; \\
\operatorname{core}\left(\mu_{P} \cup \neg \mu_{P}\right) & \supseteq \operatorname{core}\left(\mu_{P}\right) \cup \operatorname{core}\left(\neg \mu_{P}\right) \\
& =\operatorname{core}\left(\mu_{P}\right) \cup \neg \operatorname{support}\left(\mu_{P}\right) ; \\
\operatorname{support}\left(\mu_{P} \cup \neg \mu_{P}\right) & =\operatorname{support}\left(\mu_{P}\right) \cup \operatorname{support}\left(\neg \mu_{P}\right) \\
& =U .
\end{aligned}
$$


The core-support structure of a $s$-fuzzy set connects the core and support of the fuzzy set and the ones of its complement. The cores and supports of fuzzy set-theoretic operations and the set-theoretic operations of prototype sets are explored.

\section{Conclusions}

This paper presents a constructive model of fuzzy sets, which is motivated by both the concept of constructive mathematics [1] and the fact that we must have some information or knowledge about the relationships between objects in dealing with a vague concept [21]. In this model, a fuzzy set is derived from a prototype set. Each prototype forms an elementary fuzzy set based on the knowledge about relationships between objects. The knowledge is related to the basic measurement of quantities, such as distance, frequency and cost. Elementary fuzzy sets are atomic and can be directly interpreted by the knowledge. The fuzzy set is actually built on these elementary fuzzy sets by a method.

Based on the constructive model, a fuzzy set can be constructed via an explicit, finite procedure under similarity knowledge. We call $s$-fuzzy sets the constructive fuzzy sets with similarity semantics. The membership grades of an elementary $s$-fuzzy set are the degrees of similarity of objects to a prototype. Any $s$-fuzzy set can be constructed from a set of elementary ones by union operations. The constructive method can be interpreted as a projection of a crisp set through similarity relations.

We also examined the quantitative and qualitative properties of $s$-fuzzy sets. The quantitative properties show that the similarity knowledge cannot solely interpret set-theoretic operations of $s$-fuzzy sets. The core and support of a $s$-fuzzy set need to be described by the cores and supports of the $s$ fuzzy set and its complement. The core of a $s$-fuzzy set and the support of its complement are related to the prototype set, whereas there is no direct relation connecting the support of a $s$-fuzzy set and the core of its complement with the prototype set.

\section{REFERENCES}

[1] Calder, A. Constructive Mathematics, Scientific American, 10, 134-143, 1978.

[2] Cornelis, C., Cock, M.D. and Kerre, E.E. Intuitionistic Fuzzy Rough Sets: at the Crossroads of Imperfect Knowledge, Expert Systems, 20(5), 260270, November 2003.

[3] Cross, V.V. and Sudkamp, T.A. Similarity and Compatibility in Fuzzy Set Theory: Assessment and Applications, Physica-Verlag, 2002.
[4] Dubois, D., Esteva, F., Garcia, P., Godo, L. and Prade, H. A Logical Approach to Interpolation Based on Similarity Relations, International Journal of Approximate Reasoning, North-Holland, 17(1), 1-36, 1997.

[5] Dubois, D. and Prade, H. The three semantics of fuzzy set, Fuzzy Sets and Systems, 90, 141-150, 1997.

[6] Dubois, D., Esteva, F., Garcia, P., Godo, L. and Prade, H. Similarity-based Consequence Relations, ECSQARU 1995, 171-179, 1995.

[7] Dubois, D. and Prade, H. Similarity-based Approximate Reasoning, Computational Intelligence Imitating Life, Zurada, Marles \& Robinson eds., IEEE press, New York, 1997.

[8] Höhle, U. Quotients with respect to Similarity Relations, Fuzzy Sets and Systems, 27, 31-44, 1988.

[9] Kandel, A. Fuzzy Mathematical Techniques with Applications, AddisonWesley Publishing Company, Inc., 1986.

[10] Kaufmann, A. Introduction to the Theory of Fuzzy Subsets: Volume 1 Fundamental Theoretical Elements, Academic Press Inc., New York, 1975.

[11] Klir, G.J. and Wierman, M.J. Uncertainty-based Information: Elements of Generalized Information Theory, Physica-Verlag, 1999.

[12] Klir, G.J. and Yuan, B. Fuzzy Sets and Fuzzy Logic: Theory and Applications, Prentice Hall, New Jersey, 1995.

[13] Lin, T.Y. Qualitative Fuzzy Sets: A comparison of three approaches, Proceeding of Joint 9th IFSA World Congress and 20th NAFIPS International Conference, Vancouver, Canada, pp.2359-2363, July 25-28, 2001.

[14] Ovchinnikov, S.V. Similarity Relations, Fuzzy Partitions, and Fuzzy Orderings, Fuzzy Sets and Systems, 40, 107-126, 1991.

[15] Ovchinnikov, S.V. Structure of Fuzzy Binary Relations, Fuzzy Sets and Systems, 6, 169-195, 1981.

[16] Pawlak, Z. and Skowron, A. Rough Membership Functions, in: Advances in the Dempster-Shafer Theory of Evidence, Yager, R.R., Fedrizzi, M. and Kacprzyk, J. (Eds.), John Wiley and sons, New York, 251-271, 1994.

[17] Pawlak, Z. Rough Sets, Theoretical Aspects of Reasoning about Data, Kluwer Academic Publishers, Dordrecht, 1991.

[18] Santini, S. and Jain, R. Similarity Measures, IEEE Transactions on Pattern Analysis and Machine Intelligence, 21(9), 871-883, 1999.

[19] Schweizer, B. and Sklar, A. Probabilistic Metric Spaces, North-Holland, Amsterdam, 1983.

[20] Tversky, A. Features of Similarity, Psychological Review, 84(4), 327352, 1977.

[21] Yao, Y.Y. Semantics of Fuzzy Sets in Rough Set Theory, LNCS Transactions on Rough Sets, 2, 310-331, 2004.

[22] Yao, Y.Y. and Zhong, N. Granular Computing Using Information Tables, Data mining, Rough Sets and Granular Computing, Physica-Verlag Heidelberg, New York, 102-124, 2002.

[23] Yao, Y.Y. Granular Computing Using Neighborhood Systems, Advances in Soft Computing: Engineering Design and Manufacturing, The 3rd On-line World Conference on Soft Computing (WSC3), June 21-30, 1998, Roy, R., Furuhashi, T., and Chawdhry, P.K. (Eds), Springer-Verlag, London, 539-553, 1999.

[24] Yao, Y.Y. A Comparative Study of Fuzzy Sets and Rough Sets, Information Sciences, 109, 227-242, 1998.

[25] Zadeh, L.A. Similarity Relations and Fuzzy Orderings, Information Science, 3, 177-200, 1971.

[26] Zadeh, L.A. Fuzzy sets, Information and Control, 8, 338-353, 1965.

[27] Zhang, B. and Zhang, L. Theory and Applications of Problem Solving, North-Holland, Amsterdam, 1992. 